\title{
TRATAMENTO DE DADOS QUIIMICOS E MODAIS DE ROCHAS ALCALINAS DA BORDA ORIENTAL DA BACIA DO PARANÁ
}

\author{
ROSA MARIA COTRIM SOARES*
}

\begin{abstract}
The available chemical and modal petrographic analysis for alkaline rocks of oriental border of the Paraná Basin compiled from the geological literature are considered. Several petrogenetic indexes and parameters were calculated and some variation diagrams were plotted selecting the types that are the most adequate to represent world provinces. Data from basaltic rocks were also plotted in order to confront them with the tectonically closely related alkaline rocks. Some multivariate statistical methods were used in order to describe and to classify compositional types and fields. Univariate Statistical Analysis, applied to major oxides, was also considered and histograms and cumulatve frequency curves were drawn. An integrated approach combines the chemical and petrographical data into diagrams, in accordance with current geotectonic and petrological models and for comparing CIPW norms and modal data. The results demonstrate that the graphs drawn with data from Multivariate Statistical Analysis, mainly Factor Analysis, are helpful descriptive tools of the chemical composition of the several massifs, showing petrographic associations and provinces. The histograms of Differentiation Indices and Niggle quartz numbers are also helpful in the discrimination of populations. It is suggested that the peaks and compositional gaps have a petrological meaning. Brief petrologic considerations provide a contribution to the geochemistry of these alkaline rocks and indicate that the processes of fractional crystallization may partly account for the formation of these rocks.
\end{abstract}

INTRODUÇÃo Dados referentes a cerca de 200 análises químicas de rochas alcalinas da borda oriental da Bacia do Paraná, sem seleção prévia, constituem a amostra preliminar que serviu de base para o presente tratamento geoquímico interpretativo.

0 erro amostral tende a ser grande pois o número de amostras por unidade petrográfica e por maciço é em geral pequeno (alguns são desprovidos de amostras) e por não ser esse número proporcional à variança amostral a nivel de unidade petrográfica e maciço (Miesch 1967). $O$ erro analitico tende a ser também grande porque as amostras foram analisadas em diferentes laboratórios e em diferentes épocas, embora esses erros possam ser avaliados criticamente considerando as evidências geológicas e apropriadas técnicas estatísticas (Shaw 1961).

Apesar dos prováveis erros amostrais e analíticos referentes às análises químicas, os dados de concentração de elementos maiores dessas rochas alcalinas, determinados por métodos clássicos, foram utilizados para computar as estatísticas amostrais e obterem-se dados de síntese. Neste caso, as inferências a respeito das populações são inteiramente subjetivas, sem base probabilística (Krumbein \& Graybill 1965).

Por outro lado, foram também consideradas 300 análises modais de rochas alcalinas brasileiras utilizadas para comparação com as composiçôes mineralógicas normativas, de acordo com procedimentos referentes a várias províncias mundiais (Wimmenauer 1974). Do mesmo modo que os dados de análise química, as modas foram compiladas da literatura. Assim, novamente, maciços maiores e de grande variança amostral, como Poços de Caldas, apresentaram um número pequeno de análises enquanto que de outros, tais como Tapira e Salitre, desconhecem-se dados referentes a composiç̋es mineralógicas modais.

A partir das análises químicas foram determinados vários parạmetros petrológicos (números de Niggli, índices QLM, composições normativas, porcentagens e índices agpaíticos) por meio do programa de computador Norma (Amaral 1967) e traçados diagramas de variação para o conjunto de rochas supostamente aparentadas (rochas do mesmo maciço e eventualmente agrupadas segundo critérios geotectônicos). Selecionaram-se prioritariamente os parâmetros petrológicos já escolhidos para definir outras províncias mundiais, tais como o diagrama QLM (Niggli-Burri, in Burri 1964); os gráficos $\mathrm{SiO}_{2} /$ álcalis (MacDonald \& Katsura 1964) e Si/R (Jung \& Brousse 1962); os diagramas triangulares AFM e NaKCa (Nockolds \& Allen 1954); os triângulos QAP e FAP (IUGS 1973) e o diagrama petrogenético residual QNeKp (Bowen 1937).

São apresentadas as estatísticas amostrais descritivas para as rochas alcalinas da borda oriental da Bacia do Paraná referentes aos vários tipos petrográficos, maciços e provín cias (para detalhes do tratamento estatístico, ver Soares 1984). Histogramas e gráficos de freqüência acumulativa foram traçados para os vários elementos em forma de óxidos para efeito de delimitação e análise de população. Gráfi$\cos$ de frequêencia foram também analisados em função do número $q z$ e $I D$ para discriminar rochas alcalinas e detectar prováveis lacunas composicionais.

Várias técnicas estatísticas multivariadas foram utilizadas no trabalho original (Soares 1984). Neste trabalho será apresentada apenas a análise fatorial, que mostrou ser a mais adequada técnica multidimensional, que define claramente as relaçōes entre amostras e variáveis e a influência de cada fator na composição química dos diversos maciços e províncias. Por outro lado, foram comparados os resultados gerais obtidos para rochas alcalinas e basálticas e reprojetadas essas amostras em gráficos bidimensionais em relação aos fatores principais.

APRESENTAÇÃO DOS RESULTADOS Tratamento de Dados Do total de cerca de 50 maciços citados 
na literatura regional, 20 são amostrados e, destes, oito têm um número significativo de amostras, principalmente os referentes a trabalhos recentes de tese. Cerca da metade das amostras consideradas não está representada em mapas geológicos. As amostras localizadas referem-se aos.maciços de Itapirapuã (Gomes 1967), Tunas (Fuck 1972), Juquiá (Born 1971), Iporá (Danni 1974), Santa Fé (Souza 1978) e Jacupiranga (Amaral 1978). Outras amostras consideradas correspondem a análises químicas de elementos maiores cujas referências estão em Barbosa (1933), Johannsen (1938), Freitas (1947a, b), Harder (1952), Melcher (1954), Guimarães (1960), Guimarães \& Dutra (1962), Ribeiro Filho (1967), Hennies (1968), Moniz (1969), Coutinho \& Melcher (1973), Herz (1977) e Almeida (1977). Os dados modais, também omitidos no presente trabalho, estão listados em Soares (1984) e representados convenientemente em gráficos (vide Figs. 6 e 8, adiante). Os dados sobre ele- mentos-traços apresentados no trabalho original (Soares 1984) não foram aqui considerados.

\section{CALCULOS E GRAFICOS PETROQUIMICOS Diagrama} $\mathrm{SiO}_{2} /$ Alcalis $\mathrm{O}$ diagrama $\mathrm{SiO}_{2} /$ álcalis aplicado às rochas alcalinas da borda oriental da Bacia do Paraná mostra concentração de pontos acima do traço do plano crítico de sa. turação, com exceção de algumas amostras ultramáficas de Iporá e Santa Fé (Fig. 1). Comparando com os resultados obtidos para as rochas basálticas da Bacia do Paraná (Ruegg 1975), observa-se uma certa continuidade entre os campos composicionais, até com superposição parcial de campos de Tunas, São Sebastião e Iporá com as rochas basál ticas, o que poderia supor não haver aparentemente um espaço composicional de rochas basáltico-toleíticas, rigidamente separado do campo alcalino por um plano crítico de saturação, como sugerem MacDonald \& Katsura (1964) no Havaí.

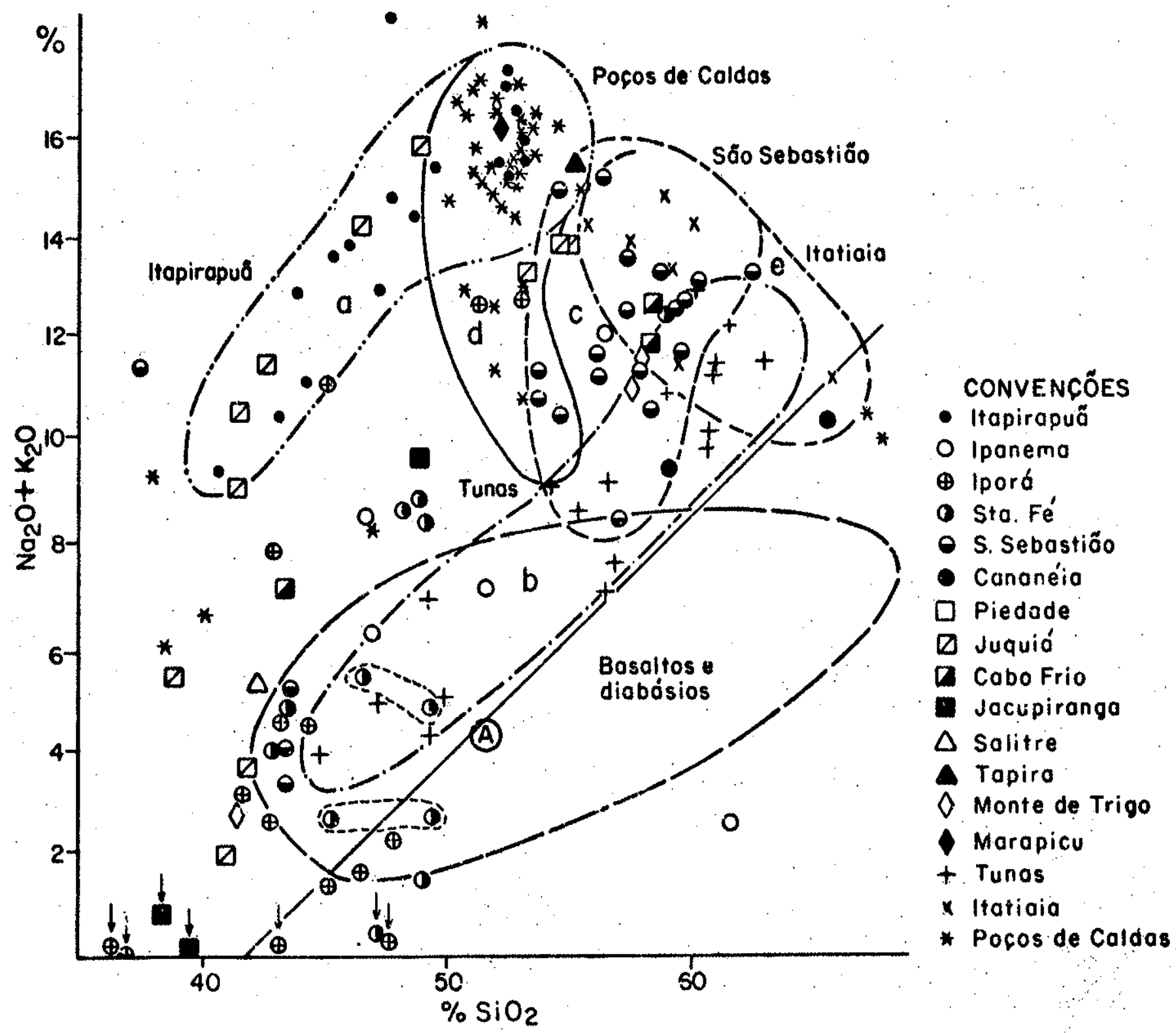

Figura 1 - Diagrama $\mathrm{SiO}_{2}$ /álcalis para as rochas alcalinas da borda oriental da Bacia do Paraná. Observa-se o traço do plano critico de saturação de MacDonald \& Katsura (1984), o ponto A correspondente à média das rochas basálticas da Bacia do Paraná (Ruegg 1975) e os vários campos composicionais de Itapirapuã (a), Tunas (b), São Sebastiäo (c), Poços de Caldas (d) e Itatiaia (e). As setas indicam as rochas acumuladas 
chas basáltico-toleíticas, rigidamente separado do campo alcalino por um plano crítico de saturação, como sugerem MacDonald \& Katsura (1964) no Havaí.

O Maciço de Tunas apresenta rochas que se situam pouco acima do traço do plano crítico de saturação indicando um comportamento saturado e relativa diferenciação em $\mathrm{SiO}_{2}$, enquanto as rochas do Maciço de Itapirapuã (da mesma "província" do Arco de Ponta Grossa) mostram caráter mais insaturado. As rochas dos maciços de São Sebastiâo e Itatiaia mostram um comportamento intermediário, posicionando-se entre Itapirapuã e Tunas, e com algumas superposições composicionais. Quanto aos maciços alcalino-ultramáficos, como Juquiá, Iporá e Santa Fé, apresentam algumas diferenças marcantes apesar de terem em comum a ampla margem de variação composicional.

Os dados da figura 1 aparecem resumidos na figura 2 , na qual se identificam ainda os Indices de diferenciação-ID (Thornton \& Tuttle 1960) e os valores normativos de nefelina ou quartzo, definindo a ampla margem de variação composicional deste grupo de rochas. Comparando esses. valores com os obtidos por Upton (1974) para as rochas alcalinas da Província de Gardar, verifica-se que em ambos os casos o número de amostras, a área de ocorrência regional e a variação composicional são semelhantes apesar de apresentarem diferentes idades. Nesse trabalho, Upton. (1974) adota o conceito amplo de província petrográfica considerando as rochas de Gardar como pertencentes a uma única província.

Diagrama $R / S i$ : O diagrama $\mathrm{R} / \mathrm{Si}$, de Jung \& Brousse (1962), no qual $\mathrm{R}=\mathrm{K}+\mathrm{Na} / \mathrm{K}+\mathrm{Na}+\mathrm{Ca}$, foi utilizado por Wimmenauer (1974) para representar a Província Alcalina Vulcânica da França, delimitando séries saturadas e insatu. radas. Danni (1974) utilizou o mesmo diagrama para as rochas alcalinas de Iporá.

Outra vez as rochas alcalinas da borda oriental da bacia mostram neste diagrama uma grande variação composicional, tanto para os índices $\mathrm{R}$ como Si (Fig. 3) e algumas se situam aquém do traço do plano crítico de saturação. Em relação aos maciços individuais são observados o paralelișmo composicional entre Itapirapuã e Tunas (menor \% Si para igual \% de $\mathrm{R}$, para o primeiro maciço e caráter acentuadamente mais insaturado do mesmo), uma pequena variação composicional para os maciços de São Sebastião e Poços de.

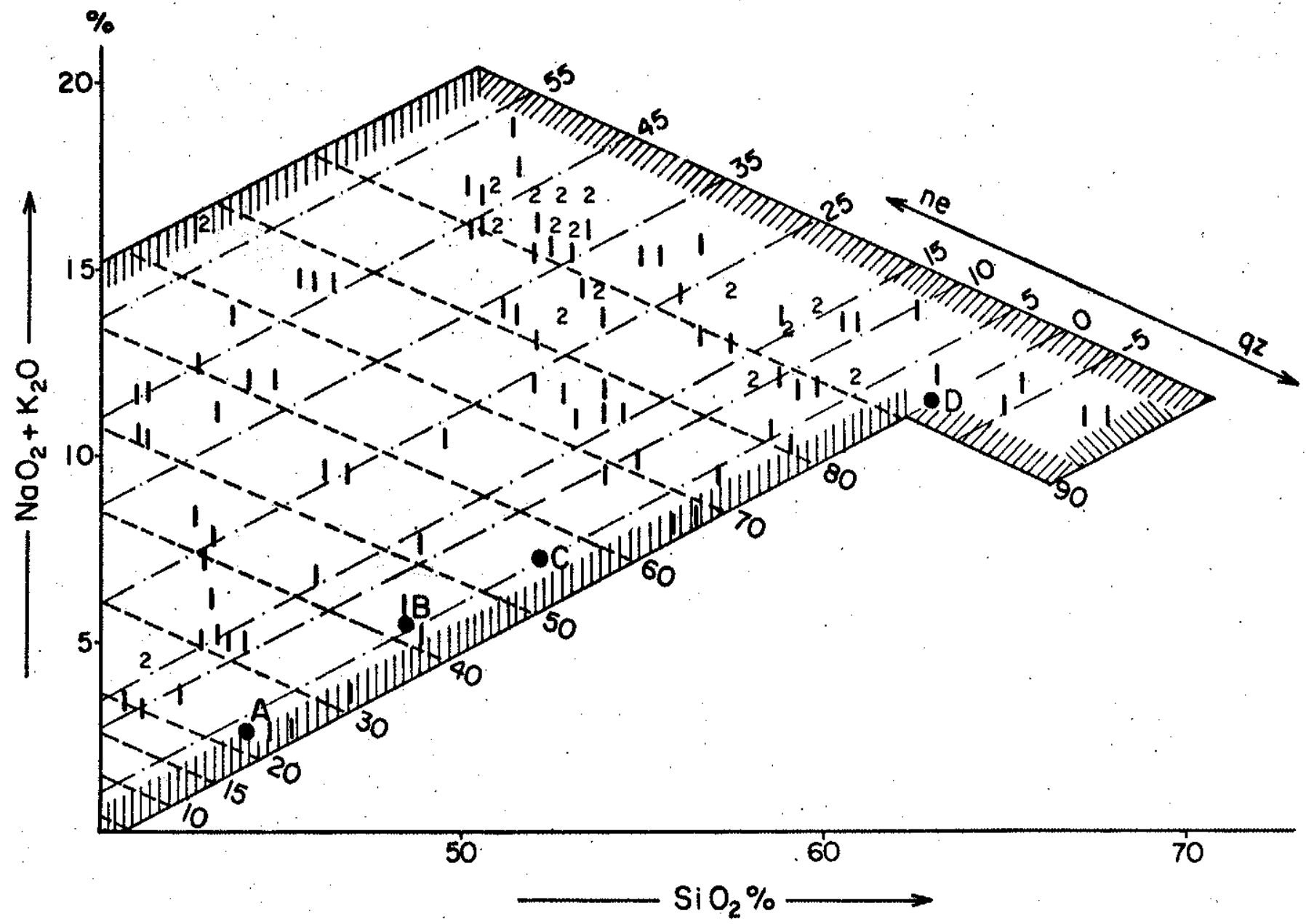

Figura 2 - Diagrama Silica/Alcalis mostrando o limite composicional das rochas alcalinas da borda oriental da Bacia do Paraná $e$ os traços dos planos de subsaturação e supersaturação (NE-SW) e dos Indices de Diferenciação (NW-SE), de acordo com a técnica de Análise de Superfície de Tendência. Os pontos $\mathbf{A}, \mathbf{B}, \mathbf{C}$ e $\mathbf{D}$ referem-se às médias para basaltos alcalinos, havaitos; mugearitos e traquitos do Havai (Upton 1974) 


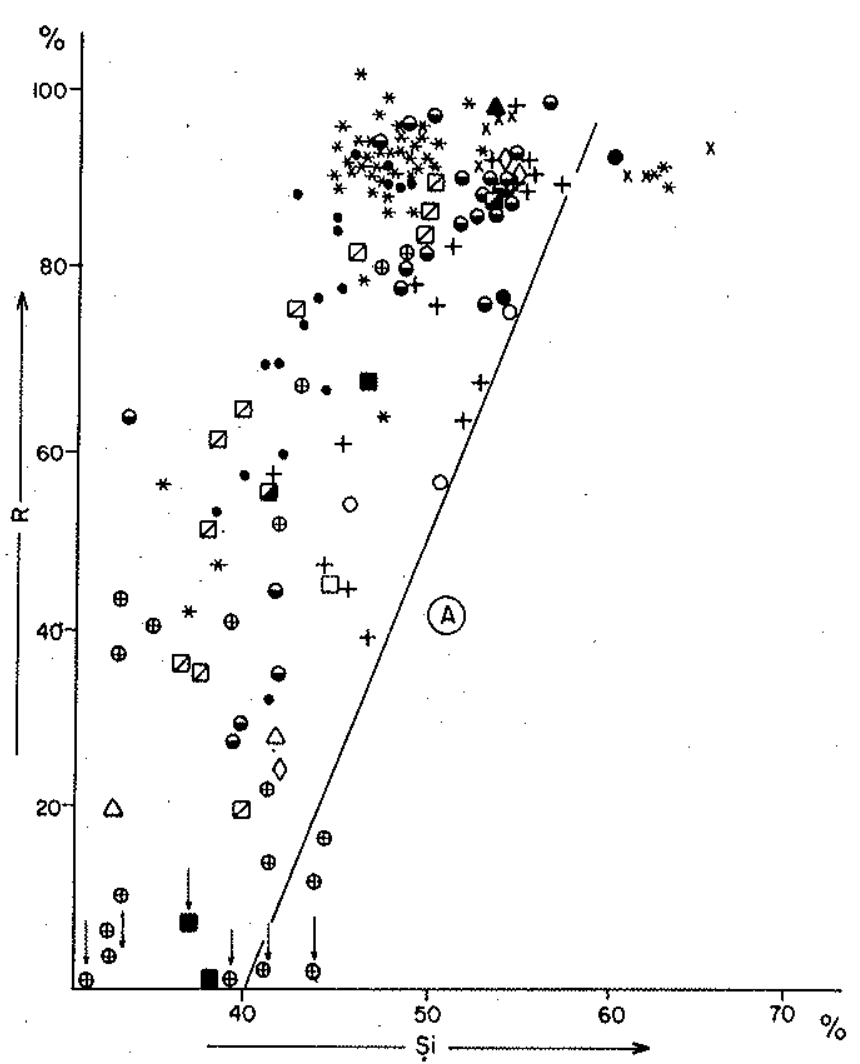

Figura 3 - Diagrama R/Si para as rochas alcalinas da borda oriental da Bacia do Paraná. Observa-se o traço do plano critico de saturafão de Jung-Brousse e o ponto A correspondente à média das rochas basálticas (Ruegg 1975). As setas indicam rochas cumuladas. As convenfões encontramse na figura 1)

Caldas, e uma forte dispersão para os maciços alcalino-ultramáficos de Juquiá, Iporá e Santa Fé.

Diagrama Q QNeKp (Sistema Petrogenético (Residual) Bowen (1937) mostrou que as rochas com feldspatóides aparecem representadas no diagrama ternário QNeKp, na área coincidente com o vale térmico insaturado, determinado experimentalmente.

Considerando apenas as rochas alcalinas com ID $>80$ foram projetadas as amostras de rochas de acordo com seus valores normativos de quartzo, nefelina e leucita no triângulo de Bowen. As rochas alcalinas do litoral do Rio de Janeiro-São Paulo situam-se no vale térmico determinado por Bowen. As rochas alcalinas do Maciço de Tunas ocupam também a mesma posição enquanto as rochas dos maciços de Itapirapuã e Poços de Caldas se situam fora da área experimental determinada por Bowen (Fig. 4). Uma explicação plausível para o deslocamento composicional das rochas desses últimos maciços pode ser considerada à luz dos dados experimentais de Wyllie \& Tuttle (1961), os quais demonstraram que, a diferentes pressões de voláteis, o vale térmico é deslocado no sentido Kp.

Diagramas Triangulares $\mathrm{AFM}$ e $\mathrm{NaKCa}$ O diagrama AFM mostra um campo composicional bem definido para o conjunto de rochas alcalinas e também individualmente para os maciços de Itapirapuã e Iporá, embora apresente uma certa dispersão para o Maciço de Tunas enquanto o Maciço de Poços de Caldas mostra uma tendência à disper. são pronunciada (Fig. 5a). Em relação às rochas basálticas da Bacia do Paraná verificam-se alguma superposição composicional e um valor médio para essas rochas próximo ao campo composicional das rochas alcalinas (Ruegg 1975).

O diagrama catiônico NaKCa apresenta uma relativa dispersão de pontos e alguma superposição composicional com - campo dos basaltos toleíticos da Bacia do Paraná. Os maciços de Tunas e Iporá mostram tendências composicionais bem definidas enquanto Itapirapuã, Poços de Caldas e São Sebastião, campos composicionais com relativa dispersão (Fig. 5b).

Comparação entre Composição Normativa e Modal A comparação entre dados de análises normativas e modais foi utilizada por Wimmenauer (1974) no estudo de algumas séries alcalinas da Europa Central e França. $O$ autor tenta delimitar vários campos composicionais utilizando gráficos QLM (normativo) e QAPF (modal). Burri (1964) considera que as relaçбes mútuas entre a composição química e a mineralógica são de grande significado petrológico.

Com base nos diagramas QLM (Niggli-Burri apud Burri 1964) e QAPF (IUGS) 1973) tenta-se delimitar também alguns campos composicionais para as rochas alcalinas da borda oriental da Bacia (Fig. 8), otendo-se para cada composição química a correspondente composição mineralógica, permitindo também avaliar os prováveis erros analíticos e comparar os resultados dessas províncias com outras mundiais publicadas na literatura geológica.

As rochas alcalinas de Itapirapữ estão constituidas principalmente de nefelina sienitos (fóide sienitos, segundo Streckeisen 1967). Esse tipo petrográfico representa um campo bem delimitado, tanto no duplo triângulo QAPF quanto no triângulo QLM. As rochas do Maciço de Tunas, formadas principalmente de sienitos alcalinos, sienitos alcalinos com fóide e monzodiorito-diorito e gabro com e sem fóides, constituem um campo bem definido nas figuras 6,7 e 8. Os maciços alcalino-ultramáficos de Juquiá e Jacupiranga apresentam algumas particularidades petrográficas. Assim, o Maciço de Juquiá mostra uma composição próxima aos fóides sienitos e foidolitos, com paragênese feldspato-feldspatóide para os membros intrusivos e com plagioclásio para algumas amostras de diques, em parte coincidente com o campo composicional de Tunas (monzodiorito e dioritos com e sem fóide), embora essas amostras não apareçam no gráfico QLM. Por outro lado, o Maciço de Jacupiranga (Amaral 1978) apresenta paragênese feldspatofeldspatóide (fóide sienitos), feldspato alcalino-plagioclásio (monzodiorito e monzogabros com e sem fóides) e membros intermediários (monzosienitos com fóides e essexitos). Com base nesta composição mineralógica, pode-se extrapolar a provável composição química dos seus diferenciados máficos e sálicos, comparando o posicionamento das amostras representadas no gráfico QAPF e no equivalente normativo QLM (Figs. 6 e 7). A rara amostra sálica desse maciço (Fig. 7) situa-se próximo ao campo de Tunas, à semethança das alcalinas de Cananéia.

As rochas alcalinas de lporá apresentam-se bem diferenciadas, com composição correspondente de fóide sienitos a piroxenitos, passando pelos membros intermediários (fóide monzosienito, essexito e teralito). As rochas alcalinas de Santa Fé estão contidas no campo composicional de Iporá (Fig. 6).

A maioria das rochas alcalinas de Poços de Caldas encontra-se no campo composicional correspondente a fóide sienitos (lado AF) enquanto o Maciço de São Sebastião mostra . 

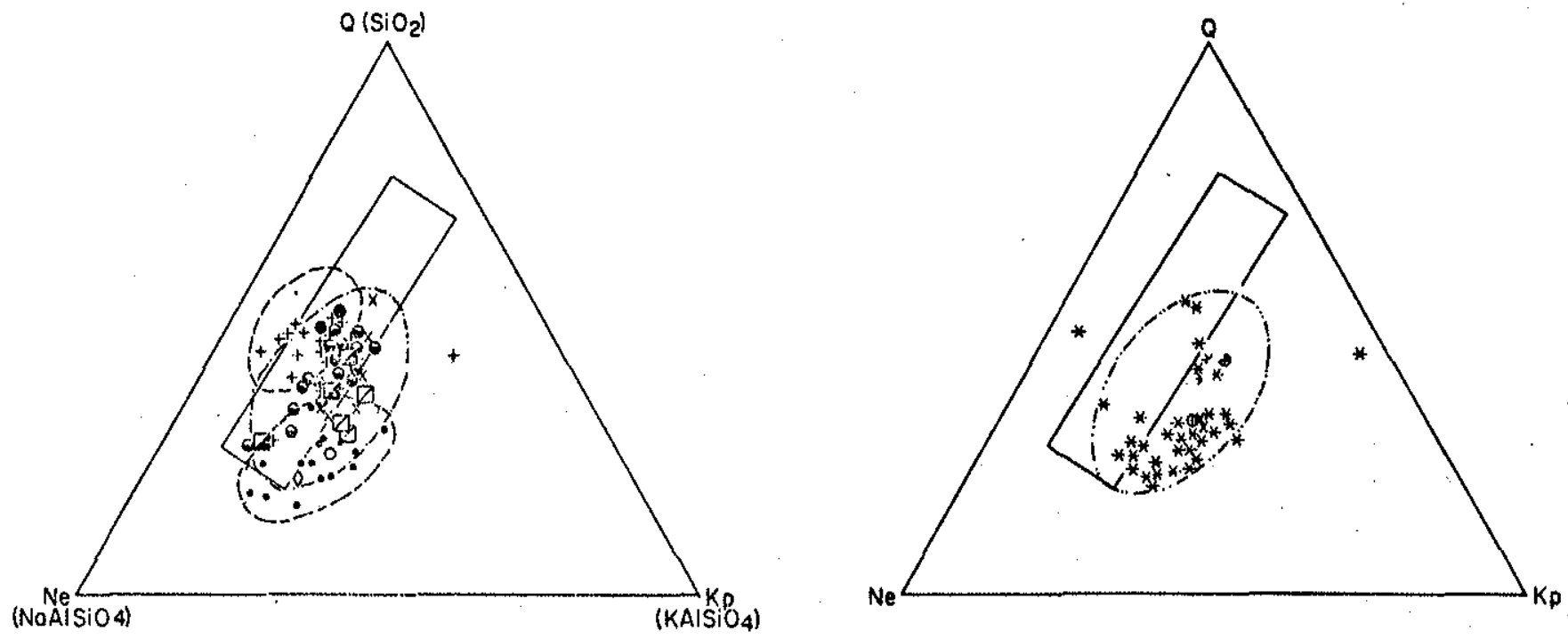

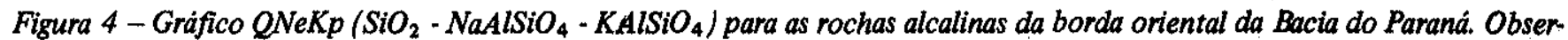
va-se a posição das amostras em relação à área experimental determinada por Bowen (1937) e o deslocamento do eutético em direçäo Kp. As convenções encontram-se na figura 1

um campo em parte contido no de Tunas e em parte no de Itapirapuã, constituindo uma área de união entre esses dois campos. O Maciço de Itatiaia apresenta um campo composicional em parte coincidente com o de São Sebastião (Província Serra do Mar), embora em ambos os gráficos seja ressaltada uma zona supersaturada (Fig. 8). O Maciço de Monte de Trigo apresenta grande número de análises modais, embora tenha um número limitado de análises quimicas. Em relação ao gráfico QAPF, as amostras de rochas situam-se principalmente no lado AF parte no $\mathrm{AP}$, permitindo que se faça alguma comparação com o Maciço de São Sebastião (Província Serra do Mar).

0 maciço de Anitápolis apresenta a maior parte de suas amostras na linha AP (mais próximas do vértice $\mathbf{A}$ ) correspondente aos sienitos e sienitos alcalinos, afora os piroxenitos e, ainda, algumas amostras no campo dos fóides sienitos e foidolitos.

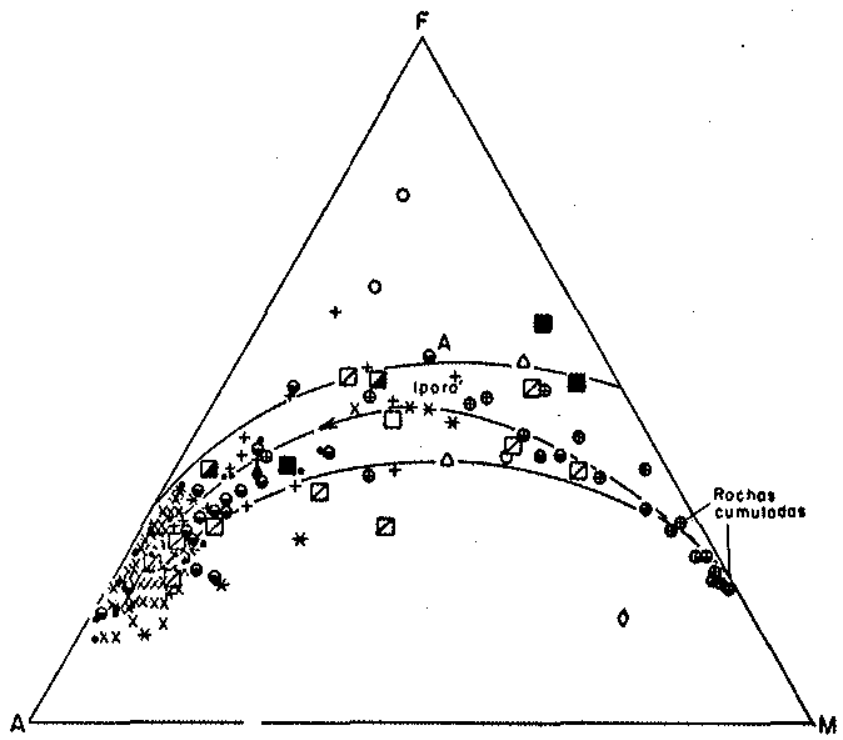

Quando as rochas alcalinas são vistas como um único conjunto, observa-se por um lado, no gráfico QLM, uma certa continuidade composicional com as rochas basálticas da Bacia do Paraná e, por outro, lacunas composicionais (Fig. 8). Essas lacunas devem ser pesquisadas para determinar seu significado físico-químico (ausência de rochas com essa composição ou mera tendenciosidade de amostragem).

As poucas amostras de rochas vulcânicas analisadas não apresentaram resultados discrepantes das plutônicas correspondentes, razão pela qual não foram discriminadas nos diagramas de variação química considerados. Também as raras amostras fenitizadas posicionaram-se nos campos composicionais gerais de rochas alcalinas

Distribuição de Freqüência Histograma de qz (Número de Niggli) Histogramas de distribuição de $q z$ foram utiliza-

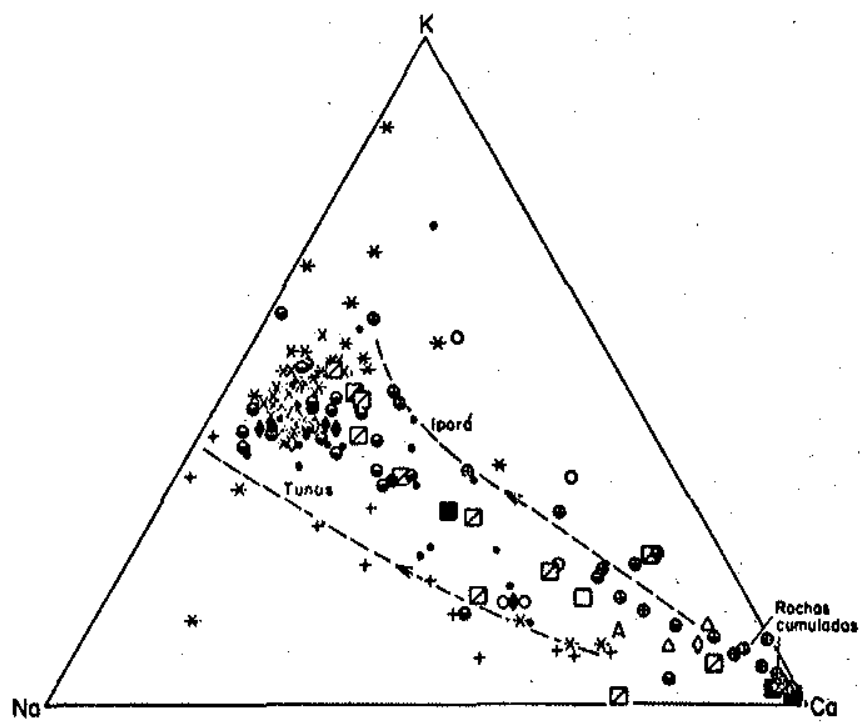

Figura 5 - Diagramas triangulares para as rochas alcalinas da borda oriental da Bacia do Paraná. O ponto A corresponde à média das rochas basálticas da bacia do Paraná, Ruegg (1975). a. FAM e b. KNaCa. Verificar o campo da suite alcalina do Havai, de acordo com Irvine \& Baragar (1971) e os trends de Tunas e Iporá. As convenföes encontram-se na figura 1 


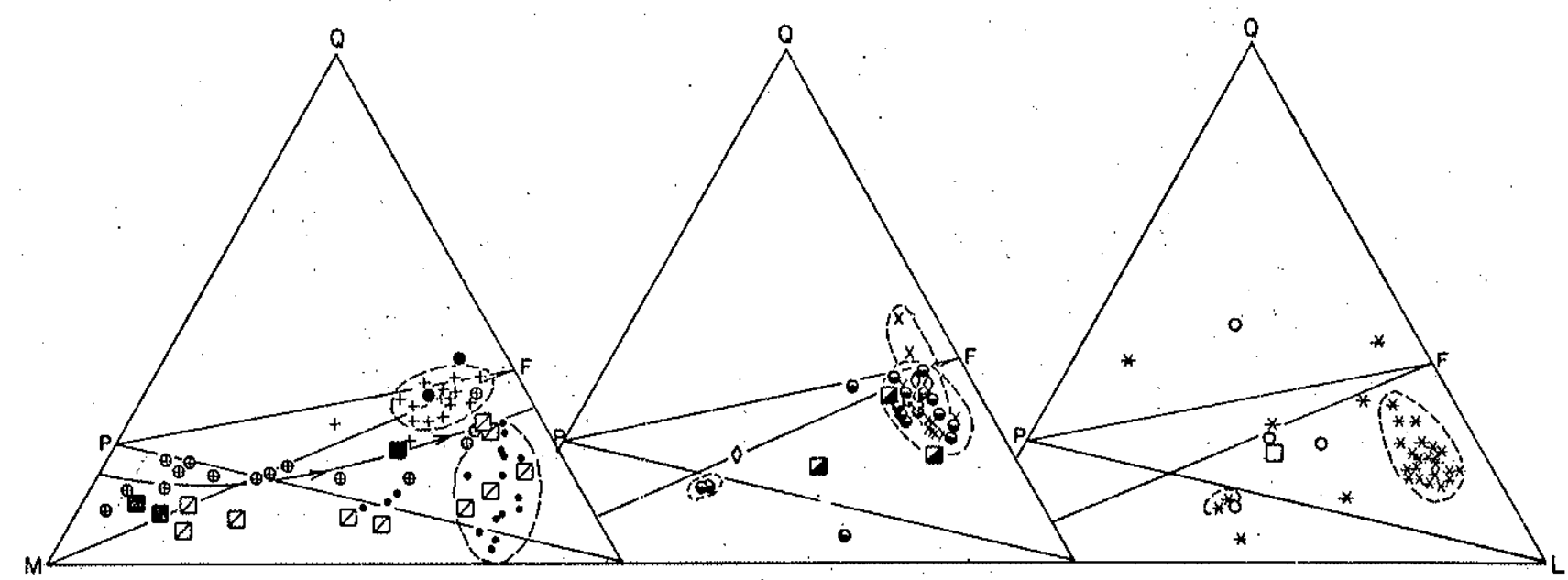

Figura 6 - Diagrama normativo QLM para as rochas alcalinas da borda oriental da Bacia do Paraná e os diversos campos composicionais dos vários maciços alcalinos (de acordo com Niggli-Burri (Burri 1964). As poucas amostras de diques analisadas näo foram discriminadas no gráfico QLM por näo apresentarem composiçōes discrepantes em relação às equivalentes plutônicas. $O$ mesmo ocorre com as raras amostras fenitizadas. As convençöes encontram-se na figura 1

dos por Burri (1964) para definir populaçбes de rochas vulcânicas do Pacífico e Atlântico.

A frequêencia de distribuição do Número de Niggli $q z$ para as rochas alcalinas da borda oriental da bacia exibe padrão bimodal insaturado, com modas entre -90 e -80 e $-40 \mathrm{e}-30$, com predominância dos valores negativos de $q z$ (Fig. 9). As rochas basálticas da bacia do Paraná mostram um padrão unimodal insaturado, com moda entre -20 a -10. A bimodalidade para as rochas alcalinas sugere duas populações diferentes, as quais podem ser mais bem analisadas se relacionadas com eventos geológicos, sendo constatato, no caso específico dos eventos geocronológicos definidos por Amaral et al. (1967), que não há coincidência composicional com os mesmos.

Histogramas $\mathrm{SiO}_{2}$ e ID $\mathrm{O}$ índice de diferenciação (ID) definido por Thornton \& Tuttle (1960), é expresso pela somatória dos componentes sálicos calculados pela norma CIPW (quartzo, ortoclásio, albita, nefelina e leucita), ou seja, ID $=\Sigma(q z+$ or $+a b+n e+l c)$. Tem sido muito utilizado pelos diversos petrólogos como parầmetro de diferenciação (Bowen 1937, Chayes 1963, Upton 1974).

Os histogramas de distribuição de ID comparados com os correspondentes $\mathrm{SiO}_{2}$ para as rochas alcalinas da Província de Gardar (Fig. 10), segundo Upton (1974), mostram um mínimo aparente para $\mathrm{SiO}_{2}$ entre $50 \%$ e $55 \%$, correspondente a ID entre $60-63$, referente à composição traquibasalto e sienograbro; de acordo com Chayes (1963), o mínimo teria um significado petrogenético e não seria meramente o reflexo de amostragem tendenciosa. Para as rochas alcalinas consideradas há também um mínimo no intervalo de $60 \%$ a $64 \%$ de ID e essa lacuna composicional é ressaltada quando são também analisadas as rochas basálticas $\mathrm{da}$ Bacia do Paraná.

Análise Fatorial : A técnica utiliza para os cálculos fatoriais é a da análise fatorial propriamente dita, com os dados padronizados e os vetores normalizados, utilizando-se os critérios de Miesch (1969), Vistelius et al. (1970) e Size (1973). Foram então determinados para as rochas alcalinas do Brasil meridional os seguintes dados, utilizàndo-se programas da série Special Package for the Social Sciences
(SPSS): a) matrizes de correlação entre variáveis; b) fatores e porcentagem de variação explicada para cada fator; $\mathbf{c}$ ) matriz fatorial e as comunalidades para as diferentes variáveis em função do número de fatores selecionados; d) matriz de coeficiente fatorial; e e) matriz de pesos fatoriais. Por outro lado, foram também reprojetadas as amostras em relação aos fatores principais em gráficos bidimensionais, os quais funcionam como os diagramas de variação da petrologia:

De acordo com a observação dos dados e gráficos anexos podem-se estabelecer as seguintes considerações:

- Em todos os maciços alcalinos analisados, um único fator (Fator I) é responsável por grande parte da variação composicional do sistema (de 55\% a 70\%) mostrando variáveis com médios e altos coeficientes de correlação. Contudo o peso das variáveis em relação aos fatores varia. $O$ comportamento dos basaltos é diferente e a porcentagem de contribuição de cada fator é menor e mais bem distribuída (Fig. 11). Desse modo, para as rochas alcalinas existe em geral uma média correlação positiva entre $\mathrm{SiO}_{2}, \mathrm{Al}_{2} \mathrm{O}_{3}$, $\mathrm{Na}_{2} \mathrm{O}$ e $\mathrm{K}_{2} \mathrm{O}$, com exceção do Maciço de Tunas (onde a alumina apresenta correlação negativa com os três óxidos citados), e forte correlação negativa do $\mathrm{SiO}_{2} \mathrm{com} \mathrm{CaO}$, $\mathrm{MgO}, \mathrm{Fe}_{\text {tot }}$ e $\mathrm{TiO}_{2}$. Em relação aos basaltos da Bacia do Paraná, a alumina apresenta correlação nula com os dois grupos de variáveis $\left(\mathrm{SiO}_{2}, \mathrm{Na}_{2} \mathrm{O}\right.$ e $\mathrm{K}_{2} \mathrm{O} / \mathrm{CaO}, \mathrm{MgO}$ e Fetot $)$. - O gráfico de projeção das amostras em relação aos fatores mostra o grau de diferenciação química dos maciços. Observa-se, por exemplo, que a diferenciação dos maciços de São Sebastião e Poços de Caldas é muito menor que nos outros maciços e também em relação ao conjunto de rochas alcalinas. Neste sentido, é conveniente comparar os resultados obtidos da análise fatorial e os obtidos dos diagramas de variação (item anterior), sendo importante considerar que os resultados dos primeiros podem ser utilizados para selecionar os diagramas de maior poder de resolução $\mathrm{em}$ função da correlação entre variáveis. Assim, um diagrama $\mathrm{SiO}_{2} /$ alcalis tem menor poder de resolução do que um outro $\mathrm{SiO}_{2} / \mathrm{CaO}\left(\mathrm{SiO}_{2} / \mathrm{MgO}\right.$ ou Fetot $)$ devido aos menores coeficientes de correlação da variável $\mathrm{SiO}_{2}$ com os álcalis, em relação a variáveis ferromagnesianas e cálcica ( $\mathrm{Fig} .12$ ). 


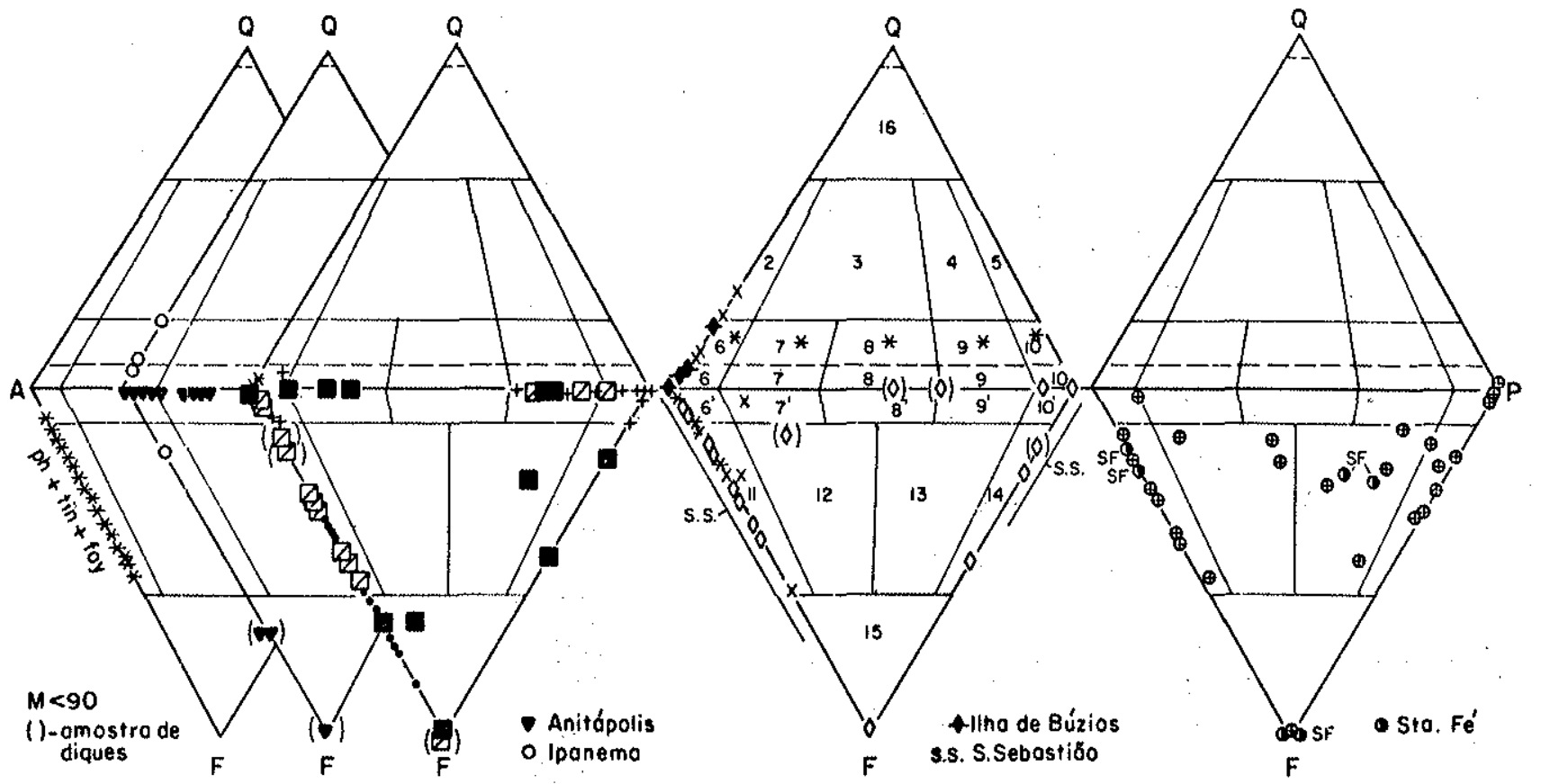

Figura 7 - Diagrama QAPF (Quartzo-Feldspato Alcalino-Plagioclásio-Feldspatóide) para as rochas alcalinas da borda oriental da Bacia do Paraná e os diversos campos composicionais dos vários maciços alcalinos de acordo com IUGS (Subcommision on the Systematics of Igneous Rocks 1973). As demais convençöes encontram-se na figura 1

DISCUSSÃO DOS RESULTADOS A integração de dados de rochas alcalinas da borda oriental da Bacia do Paraná teve como embasamento teórico hipóteses geotectônicas vigentes. Desse modo, o tratamento de dados pertinentes a essas rochas, consideradas eventualmente como uma única população, partiu de uma concepção ampla de Província petrográfica alcalina, de acordo com diversos autores (Upton, Wimmenauer, Pavlenko e Sorensen, apud Sorensen 1974a, 1974b).

A análise do conceito de província lato sensu levou-nos a admitir a idéia de que a Província alcalina do Brasil meridional constitui uma única província condicionada pela reativação wealdeniana, reforçando a idéia de divisão da mesma em sub-províncias e distritos, à semelhança de outras províncias mundiais (ver autores acima). Nesse sentido, entendemos que a utilização do conceito amplo de províncias e subprovíncia adotado por Loureiro \& Valderano (1982) seria mais adequado que o restrito estabelecido por Ulbrich \& Gomes (1981) e retomado mais tarde por Almeida (1983), sem questionar contudo as características geológicas gerais principais das províncias consagradas por esses autores. Desse modo, acrescentamos convenientemente os resultados do presente trabalho às informações já descritas mantendo a nomenclatura vigente de províncias por ser esta ainda uma questão conceitual polèmica. $O$ tratamento de dados de rochas alcalinas do Brasil meridional permitiu-nos, pois, constatar de forma suscinta as seguintes informações petrológicas:

- A Província de Poços de Caldas apresenta pouca diferenciação sílica/álcalis, o mesmo ocorrendo com a razão $\mathrm{R} / \mathrm{Si}$. Este comportamento manifesta-se também em relação ao diagrama QLM enquanto, com referência ao diagrama de Bowen (QNeKp), as rochas desse maciço encontram-se deslocadas no sentido da kalsilita. Dados de análise fatorial foram também analisados mostrando o comportamento anômalo de $\mathrm{Na}_{2} \mathrm{O}$, constituindo uma variável relativamente independente das demais.

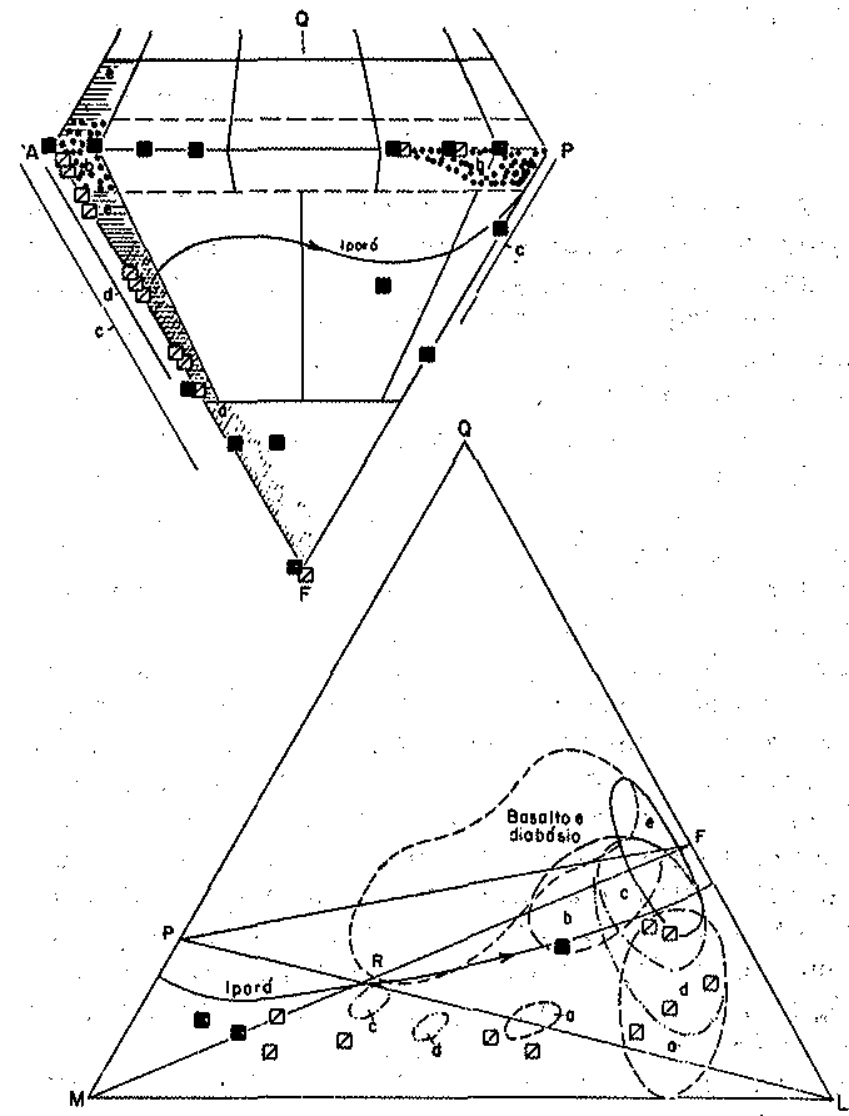

Figura 8 - Diagramas QAPF (modal) e QLM (normativo) trafados a partir dos dados das figuras 6 e 7. Verificar os vários campos composicionais dos maciços alcalinos da borda oriental da Bacia do Paraná: Itapirapuã (a), Tunas (b), São Sebastiāo (c), Poços de Caldas (d) e Itatiaia (e) e rochas basálticas do Brasil Meridional, de acordo com Wimmenauer (1974). 


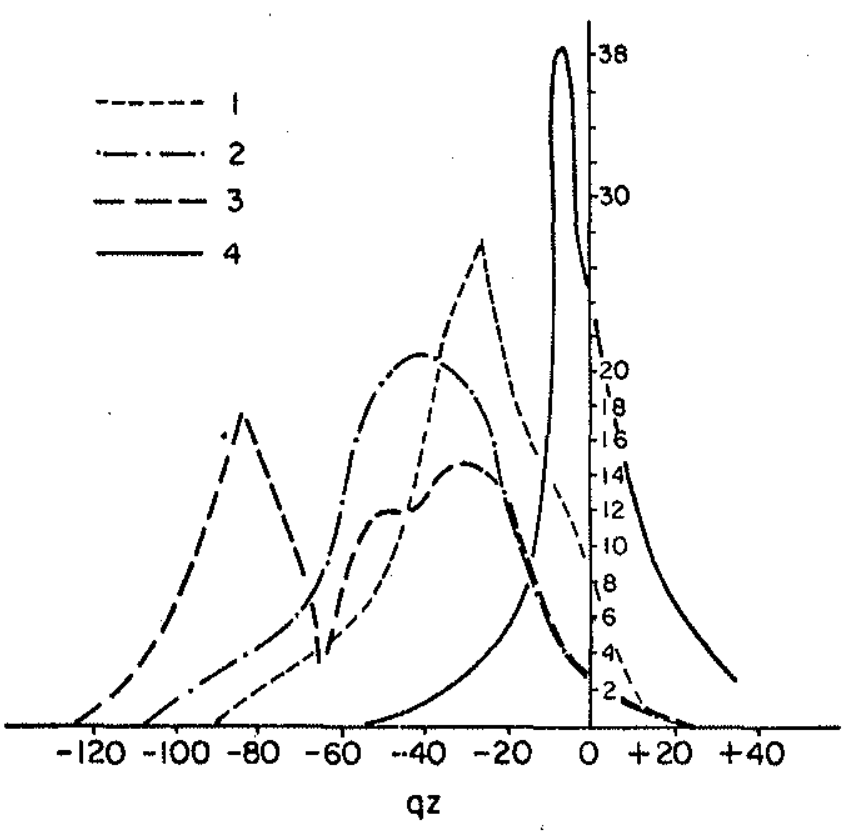

Figura 9 - Gráfico de Distribuição de Freqüência de qz (Número de Niggli) para as rochas magmáticas da Bacia do Paranä comparado com o obtido em Burri (1964) 1. Rochas vulcânicas do Pacifico; 2. Rochas vulcânicas do intraAtlântico; 3. Rochas alcalinas da borda oriental da Bacia do Paraná, 4. Rochas basalticas da Bacia do Paraná. Observar os dois picos composicionais principais para as rochas alcalinas, a -90 e -30 e, um pico para as rochas basálticas a $-10$

- As intrusões alcalinas de Iporá foram consideradas no estudo interpretativo da província de Rio Verde-Iporá, mostrando estas, em linhas gerais, uma composição bem variada e manifestada pelas composições modais, normas CIPW, índice de diferenciação, diagramas $\mathrm{Si} / \mathrm{R}, \mathrm{SiO}_{2} / \mathrm{Alk}_{2}, \mathrm{QLM}$ e outros. A análise fatorial revelou também esta variação, com correlação média positiva entre $\mathrm{SiO}_{2}, \mathrm{Al}_{2} \mathrm{O}_{3}, \mathrm{Na}_{2} \mathrm{O}$ e $\mathrm{K}_{2} \mathrm{O}$, forte correlação negativa de $\mathrm{SiO}_{2}$ com $\mathrm{Fe}_{\text {tot }}$ e $\mathrm{MgO}$ e uma correlação praticamente nula desses dois grupos de variáveis com o $\mathrm{CaO}$.

- A província do Arco de Ponta Grossa foi considerada de acordo com seus limites atuais (Almeida 1983) e inclui os maciços de Itapirapuã, Tunas, Jacupiranga, Jiquiá e raras amostras de Cananéia. Esta análise evidenciou pelo menos três campos composicionais para as rochas da província. $O$ comportamento composicional diferencial dos maciços de Tunas e Itapirapuã manifesta-se em quase todos os gráficos derivados da análise petroquímica e estatística. $\mathbf{A}$ análise fatorial revelou uma média correlação positiva de $\mathrm{Al}_{2} \mathrm{O}_{3}$ com $\mathrm{SiO}_{2}$ e $\mathrm{K}_{2} \mathrm{O}$ para o Maciço de Itapirapuã enquanto em Tunas o $\mathrm{Al}_{2} \mathrm{O}_{3}$ apresenta correlação positiva com $\mathrm{CaO}$, $\mathrm{MgO}$ e $\mathrm{Fe}_{\text {tot. }} \mathrm{Em}$ relação ao $\mathrm{Na}_{2} \mathrm{O}$, o Maciço de Itapirapuã, à semelhança de Poços de Caldas, apresenta um comportamento independente. Ainda em relação às razões $\mathrm{Na}_{2} \mathrm{O} / \mathrm{K}_{2} \mathrm{O}$, o comportamento desses dois maciços é também evidente mostrando diferentes espessuras da crosta atravessada pelo magma ao atingir a superfície. E válido, portanto, pesquisar o significado geológico dessa diferença petrográfica tendo em vista a posição tectônica desses dois maciços, englobados numa mesma província (Almeida 1983).

- Na Província de Ipanema ressalta-se seu caráter peralcalino e metaluminoso, com altos índices agpaíticos.
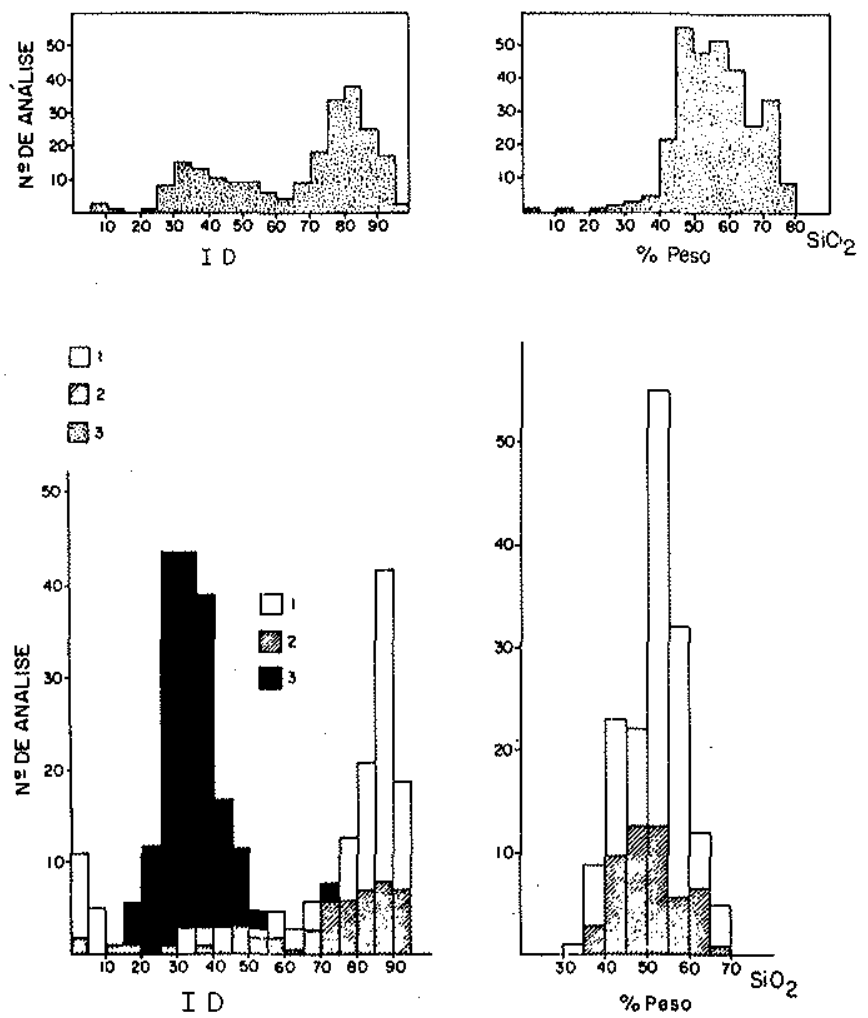

Figura 10 - Histogramas relacionando freqüência de análises quimicas de rocha e ID (Indice de diferenciação) e $\% \mathrm{SiO}_{2}$ : a) para Provincia de Hardar(Upton 1974) e b) para as rochas? alcalinas da borda oriental da Bacia do Paraná (Soares 1984). Verificar o minimo de ID entre $60 \%$ e $65 \%$ correspondente ao daly gap. 1. Rochas alcalinas da borda oriental da Bacia do Paraná; 2. Rochas alcalinas do Arco de Ponta Grossa; e. 3. Rochas basálticas da' Bacia do Paraná

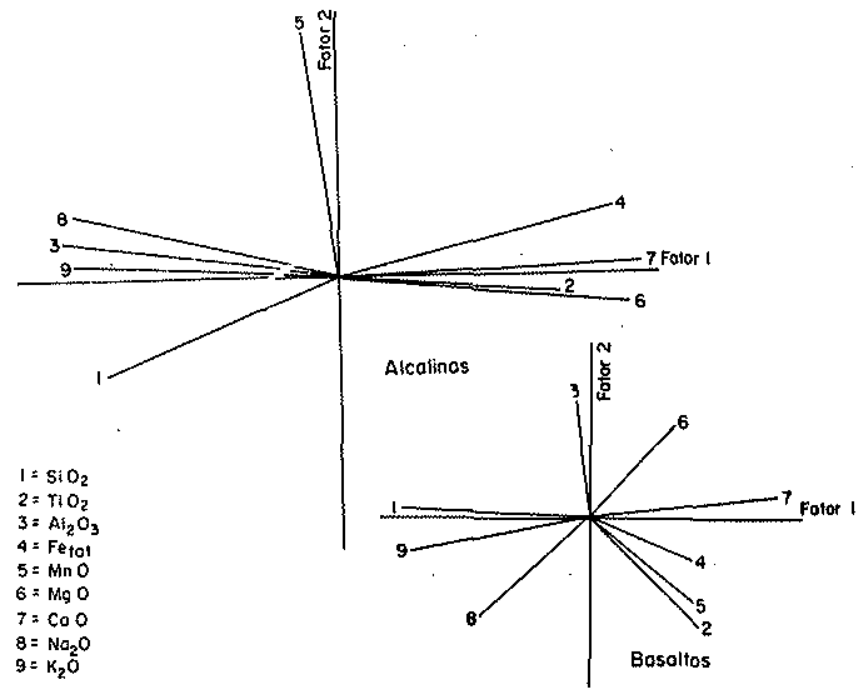

Figura 11 - Gráfico de análise fatorial para as rochas alcalinas da borda oriental da Bacia do Paraná. Correlação positiva entre $\mathrm{SiO}_{2}, \mathrm{Al}_{2} \mathrm{O}_{3}, \mathrm{Na}_{2} \mathrm{O}$ e $\mathrm{K}_{2} \mathrm{O}$ e correlação negativa de $\mathrm{SiO}_{2}$ com $\mathrm{CaO}, \mathrm{MgO}$ e Fetot. Comparar com as rochas basálticas da Bacia do Paraná (correlafão positiva do $\mathrm{SiO}_{2}$ com $\mathrm{Na}_{2} \mathrm{O}$ e $\mathrm{K}_{2} \mathrm{O}$, nula com $\mathrm{Al}_{2} \mathrm{O}_{3}$ e negativa do $\mathrm{SiO}_{2} \mathrm{com}$ $\mathrm{CaO}, \mathrm{MgO}$ e Fetot) 
- A Província Serra do Mar, acentuadamente félsica, mostra vários campos composicionais, de supersaturado (Itatiaia, Ilha de Buzios) a insaturado (São Sebastião, Monte do Trigo e Itatiaia). Foram também delimitados os vários campos composicionais dos diferenciados sálicos, mostran. do o posicionamento destes em relação ao vale térmico de Bowen. $\mathrm{O}$ gráfico da análise fatorial aplicado ao Maciço de São Sebastião mostrou média correlação positiva de $\mathrm{SiO}_{2}$, $\mathrm{Na}_{2} \mathrm{O}, \mathrm{K}_{2} \mathrm{O}$ e $\mathrm{Al}_{2} \mathrm{O}_{3}$ e altas correlações negativas de $\mathrm{SiO}_{2}$ com $\mathrm{Fe}_{\text {tot }}, \mathrm{CaO}$ e $\mathrm{MgO}$. Não foram analisados os dados

Não foram analisados os dados pertinentes às províncias do Alto Paraguai Oriental, Mariscala, Piratini, Velasco e Candelária (Almeida 1983) por não haver dados disponíveis na literatura geológica, embora se tenha conhecimento de alguns dados petrográficos reterentes à Província Piratini (Publicação Interna do IG/UFRS) e dados esparsos de Alto Paranaíba tenham sido considerados no presente trabalho. Na Província Santa Catarina, analisaram-se os dados modais do Maciço de Anitápolis, tendo-se constatato sua ampla variação petrográfica, com rochas principalmente no campo dos sienitos e sienitos alcalinos (lado AP do duplo triângulo QAPF), fóide sienitos e foidolitos (lado AF do duplo triângulo QAPF) além dos piroxenitos alcalinos (jacupiranguitos), carbonatitos e rochas fenitizadas. Quanto ao Maciço de Lages, teve-se acesso a análises químicas (Lindstaedt 1972) referentes ao mesmo, constatando-se que as rochas deste maciço têm composição correspondente a fóide sienitos miasquíticos (microfóide sienitos, tinguaítos e fonólitos). Sua posição em diagramas é próxima ao correspondente campo de Itapirapuã (lado AF do duplo triângulo QAPF).

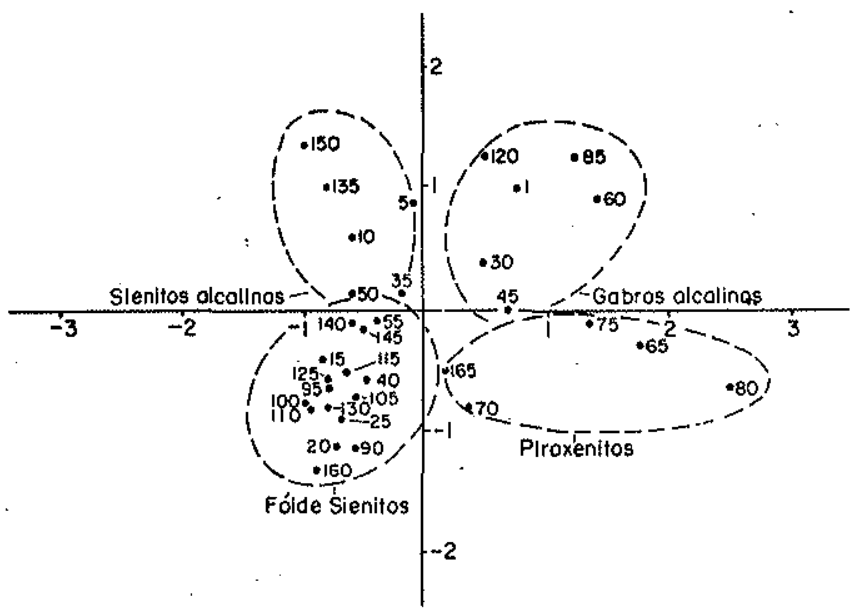

Figura 12 - Gráfico de projeção das amostras em relação aos eixos fatoriais para as rochas alcalinas da borda oriental da Bacia do Paraná. Amostras 1, 30, 60, 85 e $120=$ gabros alcalinos; $65,70,75,80$ e $165=$ piroxenitos; $5,10,35,50$, 135 e 150 = sienitos alcalinos; outras: fóide sienitos e ro chas aparentadas. Maiores detalhes em Soares (1984)

- Os vários mecanismos de formação de rochas alcalinas sấo discutidos na literatura com base em hipóteses petrogenéticas definidas, que reforçam o papel da cristalização fracionada e o caráter do nuagma parental (Coombs \& Wilkinson 1979, Green \& Ringwood 1967, Carmichael et al. 1974, Wilkinson 1974). Nesse sentido, foi considerado o provável magma parental para as diversas províncias e integradas as informações referentes ao magmatismo do
Brasil meridional, mostrando a não-existência de basaltos tipicamente alcalinos mas apenas a de enormes massas de basaltos toleíticos, raramente com olivina e desprovidos de nefelina na norma CIPW, embora tectonicamente correlacionáveis ao magmatismo alcalino (Herz 1977). Os campos composicionais desses basaltos e das rochas alcalinas foram formalizados nos vários gráficos para um confronto composicional. Kuno (1968) e Coombs \& Wilkinson (1979) forneceram revisões de possíveis trends de fracionamento de magmas basálticos alcalinos mostrando que existe um continuo espectro de linhagens de líquidos básicos e sálicos dependendo da composição do magma parental. Desse modo, um basalto moderadaniente alcalino (sem apreciável hiperstênio e nefelina a norma) poderia produzir diferenciados insaturados. Green \& Ringwood (1967) apresentaram as várias tendências de basaltos a diferentes pressões, mostrando que um olivina basalto pode dar origem a basaltos alcałlinos e, a grande pressões (nas condições da crosta inferior e manto superior), a barreira térmica entre o campo insaturado e saturado de Yoder \& Tilley (1962) pode ser rompida. Nesse sentido, é importante considerar a ocorrência, embora rara entre as rochas basálticas do Brasil meridional, de olivina basaltos e olivina basaltos toleíticos, refletindo diferentes níveis de diferenciação abissal. No SE do Brasil existem também associações esparsas do tipo diques de basalto-traquito-fonólito (Ulbrich \& Gomes 1981) formadas provavelmente por processos de diferenciação. Quanto aos equivalentes intrusivos, os processos de cristalização fracionada podem ser responsáveis pela diferenciação de gabros alcalinos em rochas do tipo fóide sienitos, ocorrentes èm Tunas, São Sebastião, Iporá e outras localidades.

- As associaçōes ultramáfico-alcalinas são interpretadas como provenientes do magma também desta natureza, rico em voláteis e com evolução controlada pela atuação dos elementos móveis como $\mathrm{CO}_{2}$ e $\mathrm{H}_{2} \mathrm{O}$. (Green \& Ringwood 1967). Uma sequiência estratificada iria dar dunitos basais e piroxenitos-urtitos até nefelina sienitos, por processos de cristalização fracionada (Danni 1974).

- Outro aspecto importante relacionado provavelmente com a cristalização fracionada refere-se à lacuna composicional (ID entre $60 \%$ e $65 \%$ ), no intervalo entre a atividade basáltica e alcalina, o chamado daly gap atribuído como de importância petrogenética. Le Maitre (1968) tem outra interpretação e mostra que essa lacuna é devido à discriminação nos processos eruptivos e não à escassez de magmas intermediários. Por outro lado, foi analisado o caráter bimodal da curva de distribuição de $q z$ (Número de Niggli) a qual evidencia dois picos composicionais, com moda entre -90 e -80 e entre -40 e -30 coincidentes aproximadamente com os picos de Itapirapuâ e Tunas, respectivamente. Considerando ainda as rochas basálticas, com uma moda entre -20 e -10 têm-se delimitadas três diferentes populaçбes de rochas magmáticas na borda oriental Bacia do Paraná.

- O resíduo sálico do fracionamento do magma parental pode ser representado em termos do sištema Qnekp "sistema petrogenético residual" e cujas principais feições foram discutidas por Bowen (1937), "Fudali (1963) e Hamilton \& Mackenzie (1965). Nas províncias alcalinas consideradas existem principalmente duas tendências dos diferenciados sálicos: a primeira representada pelas rochas alcalinas de Tunas (coincidente com a área experimental determinada por Bowen) e a segunda pelo Maciço de Itapirapuã com um campo composicional deslocado em relação ao vértice $\mathrm{Kp}$. 
As rochas alcalinas dos maciços de São Sebastião e Itatiaia, Província Serra do Mar, também situam-se na área experimental determinada por Bowen, enquanto aquelas dos maciços de Poços de Caldas, Juquiá e Iporá se encontram deslocadas no sentido da Kalsilita (Kp).

\section{CONCLUSÓES 0 tratamento de dados químicos $\mathrm{e}$} modais de rochas alcalinas da borda oriental da bacia do Paraná, expresso pelos diagramas petroquímicos e gráficos estatísticos descritivos, fornece subsídios importantes à sistemática de rochas ígneas e à interpretação geotectônica do magmatismo alcalino que afetou a Plataforma meridional do Brasil, no Mesozóico.

Em relação à sistemática de rochas ígneas, a contribuição do presente trabalho consiste em reunir um grande número de análises químicas e modais disponivel na literatura $e$ interpretada de modo restrito pelos vários au tores, representando-as em gráficos adequados, os quais permitem analisar os vários trends ígneos regionais. Nos vários trabalhos petrológicos clássicos, as séries ígneas são representadas em diagramas químicos, os quais classificam as rochas de acordo com sua composição e permitem comparar os modelos de variação composicional das várias províncias ígneas mundiais. Apesar de a classificação internacional mais recente, adotada pelo IUGS, levar em consideração apenas a composição modal das rochas ígneas, isto não significa que não sejam consideradas as diversidades de trends ígneos na interpretação dos processos de diferenciação magmática relativos às províncias. Por outro lado, ainda nesses trabalhos, as várias séries ígneas de diferente natureza são confrontadas, como ocorre com as séries alcalinas e toleítica đo Havaí, as quais servem de padrão químico composicional para outras sèries em que intervêm os dois tipos de magmas divergentes.

Em relação à tectônica, convém mencionar que as modernas teorias de deslocamento de placa levam em consideração os processos de evolução geoquímica durante a cristalização fracionada (a partir da fusão parcial do ma- terial pirolítico do manto), sendo marcantes as variações nas concentrações tanto dos elementos-traços incompativeis como nas concentrações de elementos maiores (notadamente $\mathrm{Fe}, \mathrm{Mg}, \mathrm{Na}, \mathrm{Ca}$ ), tanto a baixas como a altas pressões. Muitos trabalhos experimentais têm reconhecido a continuidade e transição na composição química entre os vários tipos de magmas nos processos de diferenciação magmática. Os resultados desses estudos conduzem à investigação do papel que a cristalização fracionada, a pressões abissais e sob condiçðes secas e úmidas, pode representar na geração de um espectro de magmas básicos. Os dados composicionais químicos e modais, ora apresentados, devem então ser comparados com esses resultados experimentais para uma reconstrução dos processos que originaram a formação dessas rochas, muitas vezes obliterados na ascensão do magma aos vários níveis crustais. Desse modo, o presente trabalho contribui para o conhecimento da geoquímica do manto, considerando que as rochas alcalinas consideradas são o testemunho do equilíbrio de fase cristal/líquido nos vários níveis de diferenciação magmática. Ainda vale considerar que os vários campos composicionais das rochas magmáticas da borda oriental da bacia podem ser correlacionados com os da crosta da África, de acordo com as modernas teorias de placas, as quais relacionam o mag matismo mesozóico ao deslocamento de placas continentais, o qual se daria segundo pontos fixos no manto e, de acordo com os geotectonistas, poderia ser reconstruído apoiado na história do magmatismo alcalino e basáltico, que afetou a Plataforma Sul-Americana.

Agradecimentos A autora agradece ao Conselho Nacional do Desenvolvimento Científico e Tecnológico (CNPq), instituição da qual foi bolsista a nível de doutorado, de 1977 a 1980 , e ao orientador da Tese de Doutorado, Professor Dr. Franco Levi. Este trabalho é uma síntese de parte da tese, intitulada Tratamento de Dados Químicos e Petroló. gicos de Rochas Alcalinas do Brasil Meridional, defendida no Instituto de Geociências da Universidade de São Paulo.

\section{REFERENCIAS BIBLIOGRAFICAS}

ALMEIDA, E.B. de - 1977 - Geology of bauxite deposits of the Pocos de Caldas District, State of Minas Gerais, Brazil. Standford-USA, 273 p. (Ph.D. Dissertation. University of Stamdford).

ALMEIDA, F.F.M. de - 1983 - Relações tectônicas das rochas alcalinas mesozóicas da região meridional da Plataforma Sulamericana, Rey, Bras. Geoc., 13(3):139-158.

AMARAL, G.; BUSHEE, J.; CORDANI, U.G.; KAWASHITA, K.; REYNOLDS, J.H. - 1967 - Potassium-argon ages of alkaline rocks from the southern Brazil. Geoch. Cosmoch. Acta, $31: 117-142$.

AMARAL, G. - 1967 - Programa para cálculos petroquímicos (Norma e Valores de Niggli) em computador. In: CONGR. BRAS. GEOL., 21, Curitiba, 1967. Anais..., Curitiba, SBG, p. $113-118$.

AMARAL, G. - 1978 - Potassium-argon age studies on the Jacupiranga Alkaline District, State of São Paulo, Brazil. In: INTERNATIONAL SYMPOSIUM OF CARBONATITES, 1 , Poços de Caldas, 1978. Anais..., Poços de Caldas, DNPM, p. 257-302.

BARBOSA, O. - 1933 - Eruptivas de Lajes, Santa Catarina. Rio de Janeiro, Serv. Geol. Mineral. 13 p. (Bol. 13d).

BORN, H. - 1971 - O Complexo Alcalino de Juquid. São Paulo. 176 p. (Tese de Doutoramento/IGUSP, inédita).

BOWEN, N.L. - 1937 - Recent high temperature research on silicates and its significance in igneous geology. Am. J. Sci., 233-234:1-21.

BURRI, J.R. - 1964 - Petrochemical calculations based on equivalents (Methods of Paul Niggli). Jerusalem. 304 p. (Program of Scientific Translations).

CARMICHAEL, I.S.E.; TURNER, F.J.; VERHOOGEN, J. - 1974 Igneous Petrology. New York, McGraw-Hill. $739 \mathrm{p}$.

CHAYES, F. - 1963 - Relative abundance of intermediate members of oceanic basaltic-trachyte association. J. Geol. Res., 68(5):1519-1534.

COOMBS, D.S. \& WILKINSON, J.F.G. - 1979 - Volcanic lineages and fractionnation trends in some undersaturated volcanic rocks and shallow intrusives from the East Otago Volcanic Province (New Zealand) and related rocks. J. Petrol., 10:440-501.

COUTINHO, J.M.V. \& MELCHER, G.C. - 1973 - Levantamento geológico e petrográfico da liha de Monte de Trigo litoral norte de São Paulo, Brasil). Rev. Bras. Geol., 3:243-256.

DANNI, J.C.M. - 1974 - Géologie des complexes ultrabasiques alcalins de la Région d'lporá, Goiás, Brésil. France (D. Sci. Thesis, Université de Paris, Sud, Centre d'Orasay.).

FREITAS, R.O. - 1947a - Geologia e petrologia da tha de São Sebastião. Bol. Fac. Fil. Cienc. Letras da USP, 85 (Geologia 3).

FREITAS, R.O. - 1947b - Eruptivas alcalinas de Cananéia. Bol. Fac. Fil. Ciênc. Letras da USP, 91 (Geologia 4).

FUCK, M.A. - 1972 - Geologia do Maciço alcalino de Tunas, Para$n a \dot{a}$, Brasil. São Paulo (Tese de Doutoramento/IGUSP, inédita).

FUDALI, R.F. - 1963 - Experimental studies bearing on the origin of pseudoleucite and associated problems of alkalic rocks systems. Bull. Geol. Soc. Am., 74:1101-1126.

GOMES, C.B. - 1967 - Petrologia do Macico Alcalino de Itapira. 
puã. São Paulo, 167p. (Tese de Doutoramento/IGUSP, inédita).

GREEN, D.H. \& RINGWOOD, E.A. - 1967 - The genesis of basaltic magmas. Contr. Miner Petrology, 15:103-190.

GUIMARĀES, D. - 1960 - Fundamentos das rochas ígneas do Brasil. DNPM/DFPM. Rio de Janeiro. 410p. (Bol. 107).

GUIMARÄES, D. \& DUTRA, C.V. - 1962 - Contribuição a geoquímica das rochas alcalinas do Brasil. Rio de Janeiro, DNPM/DFPM. 32 p. (Bol. 112)

HAMLTON, D.L. \& MACKENZIE, W.S. - 1965 - Phaseequilibrium studies in the system $\mathrm{NaAlSiO}_{4}-\mathrm{KAlSiO}_{4}-\mathrm{SiO}_{2}$ $\mathrm{H}_{2}$ O. Mineral. Mag., 34:214-231. (Tilley vol).

HARDER, E.C. - 1952 - Example of bauxite deposits illustrating variations in origin. In: SYMPOSIUM ON PROBLEMS OF CLAY AND LATERITE GENESIS. New York, 1952, Actas.. New York, Am. Inst. Min. Metall, p.35-65.

HENNIES, W.T. - 1968 - Tabelas de Análises Qutmicas de Rochas (IGUSP, inédito).

HERZ, N. -1977 - Timing of spreading in the South Atlantic. Information from Brazilian .Alkaline rocks. Geol. Soc. Am. Bull, 88:101-112.

IRVINE, T.N. \& BARAGAR, W.R. - 1971 - A. Guide to the Chemical Classification of the Common Volcanic Rocks. Can. J. Earth Sci., 8, 523-548.

IUGS - Subcommission on the Systematics of Igneous Rocks 1973 - Classification and nomenclature of plutonic rocks recommendations. Neues. Jb. Miner. Mh.; 4:149-164.

JOHANNSEN, A. - $1938-A$ Descriptive Petrography of the Igneous Rocks. 1, Chicago: Univ. Chicago Press.

JUNG, J. e BROUSSE, R. - 1962 - Les provinces volcaniques néogenés et quaternaires de la France. Bull. Serv. Carte Geól. France, 58 (267):1-61.

KRUMBEIN, W.C. \& GRAYBILL, W.A. - 1965 - An Introduction to Statistical Models in Geology. New York, McGraw-Hill, 475 p.

KUNO, H. - 1968 - Differentiation of basalt magmas. In: HESSE, H.H. \& POLDERVAART, A. (Eds.) Basalts: The Poldervaart Treatise on Rocks of Basaltic Composition. New : York, Intersciences, p. 623-658

LE MAITRE, R.W. - 1968 - Chemical variation with and between volcanic rocks series - a statistical approach. J. Petrol. 9:220-252.

LINDSTAEDT, H.P. - 1972 - A Alterą̧ão das Rochas Alcalinas. Lajes-Santa Catarina (Curso de Pós-Graduação em Geociências/UFRS, inédita).

LOUREIRO, F.E.L. \& VALDERANO, M.H.W. - 1982 - A província alcalina carbonática Brasil-Angola e seus principais aspectos econômicos. In: CONGR. BRAS. GEOL. 32, Salvador, 1982 Anais..., Salvador, SBG. v. 4, p. 1049-1060.

MacDONALD, R, \& KATSURA, T. - 1964 - Chemical composition of Hawaiian lavas. J. Petrol, , $51: 82+133$.

MELCHER, G.C. - 1954 - Nota sobrè o distrito alcalino dè Jacupiranga; São Paulo. Brazil. Rio de Janeiro, DNPM/DGM. 20p. (Notas Prel: 84).

MIESCH, A.T. - 1967 - Statistical studies in field geochemistry. Geological survey professional paper. A classification of geochemical error and discussion of their effects in data interpretation. In: UNITED STATES GOVERNMENT PRINT ING OFFICE, Washington.

MIESCH, A.T. - 1969 - Critical review of some multivariate procedures in the analysis of geochemical data. Math. Geol., 1(2):171-184.

MONIZ, A.C. - 1969 - Estudo mineralógico de argilas do maciço
Alcalino de Pocos de Caldas, MGmSP: nota preliminar. Recife. Boletim Mineralogico, $6: 31.40$.

NOCKOLDS, S.R. \& ALLEN, R. - 1954 - The geochemistry of some igneous rock. Series. Geochim. Cosmochim. Acta, $5: 245-285$.

PAVLENKO A.S. - 1974 - The Mongol Tuva Province of alkaline rocks. In: SORENSEN, H., (ed:) The Alkaline Rocks. New York, John Wiley, p. 171-293.

RIBEIRO FILHO; E. - 1967 - Macicos do Itatiaia e Passa Quatro. Bol. Fac. Fil. Cienc. Letras, p. 5-93 (Geologia 2).

RUEGG, N. - 1975 - Modelos de variação química na provtncia basáltica do Brasil Meridional. São Paulo, 309 p. 2v. (Tese de Livre-Docência; IGUSP, inédita).

SHAW, D.M. - 1961 - Element distribution Laws in geochemistry. Geoch. Cosmoch. Acta, 23:116-134. 5(2):191-197

SIZE, N.B. - 1973 - Interpretation of Factor Analysis on Modal Data from the Red Hill Syenit c Complex. Math.Geol., 5(2):191-197.

SOARES, R.M.C. - 1984 - Tratamento de dados quimicos e petro gráficos de rochas alcalinas do Brasil Meridional. São Paulo, $316 \mathrm{p}$. (Tese de Doutoramento, IGUSP, inédita).

SÖRENSEN, H. $-1974 \mathrm{a}-$ Glossary of alkaline and related rocks. In: SORENSEN, H. (ed.) The Alkaline Rocks, New York, John Wiley, p. 558-577.

SÖRENSEN, H. - 1974b - Origin of the alkaline rocks. Summary and retrospect. In: SORENSEN, $\mathrm{H}$. (ed.) The Alkaline Rocks, New York, John Wiley, p. 535-539.

SOUZA, A.M. - $1978^{-M i n e r a l o g i a ~ e ~ p e t r o l o g i a ~ d o ~ c o m p l e x o ~}$ ultramáfico, Belém, 22p. (Dissertação de Mestrado, Universidade Federal do Pará).

STRECKEISEN, A. - 1967 - Classification and nomenclature of igneous tocks. N. Jb. Miner: $A b h, 107(2): 144-214$.

THORNTON, C.P. \& TUTTLE, O.F. - 1960 - Chemistry of igneous rocks. I. Differentiation Index. Am. J. Scl., 258:664-684.

ULBRICH, H.H.G.J. \& GOMES, C.B. - 1981 - Alkaline rocks from continental Brazil. Earth Scl. Rev., 17:135-154.

UPTON, B.G.J. - 1974 - The alkaline province of South-West Greenland. In: SORENSEN, H. (ed.) The Alkaline Rocks. New York, John Wiley. p. 221-237

VISTELIUS, A.B.; IVANOV, D.N.; KURODA, Y.; RUIS FULLER, C. - 1970 - Variation of modal composition of granitic rocks in some regions around the Pacif. Math. Geol, 2(1):63-80.

WILKINSON, J.F.G. - 1974 - The mineralogy and petrography of alkaline basaltic rocks. In: SORENSEN, $H$. (ed.) The Alkaline Rocks. New York, John Wiley, p. 87-95.

WIMMENAUER, W. - 1974 - The alkaline province of Central Europe and France. In: SORENSEN, H. (ed.) The Alkaline Rocks. New York, Jón Wiley, p. 87-95.

WYLLIE, P.J \& TUTTLEO.F - 1961 - Experimental investigation of silicate systems containing two volatile components. Part II. The effects of $\mathrm{NH}_{3}$ and $\mathrm{HF}$, in addition to $\mathrm{H}_{2} \mathrm{O}$ on the melting temperatures of albite and granite. $\mathrm{Am}$. J. Sci., 259:128-143.

YODER, H.S. \& TILLEY, C.E. - 1962 - Origin of basalt magma an experimental study of natural and syntetic rock system. $j$ Petrol., 3:342-352.
MANUSCRTTO 359

Recebido em 04 de abril de 1986 Revisão aceita em 30 de março de 1987 